\title{
Assessing the magnitude and trends in hospital acquired infections in Canadian hospitals through sequential point prevalence surveys
}

Geoffrey Taylor ${ }^{*}$, Denise Gravel ${ }^{2,3}$, Anne Matlow ${ }^{4}$, Joanne Embree ${ }^{5}$, Nicole LeSaux ${ }^{6}$, Lynn Johnston, Kathryn N. Suh ${ }^{6}$, Michael John ${ }^{8}$, John Embil ${ }^{5}$, Elizabeth Henderson' ${ }^{9}$, Virginia Roth ${ }^{6}$, Alice Wong ${ }^{10}$

and the Canadian Nosocomial Infection Surveillance Program

\begin{abstract}
Background: Healthcare acquired infections (HAl) are an important public health problem in developed countries, but comprehensive data on trends over time are lacking. Prevalence surveys have been used as a surrogate for incidence studies and can be readily repeated.

Methods: The Canadian Nosocomial Infection Surveillance Program conducted prevalence surveys in 2002 and 2009 in a large network of major Canadian acute care hospitals. NHSN definitions of HAI were used. Use of isolation precautions on the survey day was documented.

Results: In 2009, 9,953 acute care inpatients were surveyed; 1,234 infections (124/1000) were found, compared to $111 / 1000$ in 2002, $(p<0.0001)$. There was increased prevalence of urinary tract infection (UTI) and Clostridium difficile, offset by decreases in pneumonia and bloodstream infection. Use of isolation precautions increased from 77 to 148 per 1000 patients ( $<<0.0001$ ), attributable to increased use of contact precautions in patients infected or colonized with antimicrobial resistant organisms.

Conclusion: Between 2002 and 2009 HAl prevalence increased by $11.7 \%$ in a network of major Canadian hospitals due to increases in Clostridium difficile and urinary tract infection. The use of isolation precautions increased by 92. $2 \%$ attributable to increased contact isolation. National prevalence surveys are useful tools to assess evolving trends in HAl.
\end{abstract}

Keywords: Healthcare acquired infection, Isolation precaution, Prevalence, Canada

\section{Background}

Hospital acquired infections (HAI) are a common complication of healthcare, but determining their frequency and assessing trends over time is difficult [1]. For the most part HAI are not notifiable in Canadian provinces. Comprehensive continuous surveillance for all HAI within hospitals is time and labour intensive, consequently very few hospital Infection Prevention and Control (IPC) programs conduct this type of surveillance. Nevertheless,

\footnotetext{
* Correspondence: geoff.taylor@ualberta.ca

'University of Alberta Hospital, 1-127 CSB, T6G 2 G3 Edmonton, Alberta, Canada

Full list of author information is available at the end of the article
}

there is a need to determine the extent, subtypes and trends in HAI over time so that national, provincial and local practitioners and policy decision makers can identify priorities for preventive action. Comprehensive, multi-institutional prevalence surveys for the occurrence of HAI have been adopted as a cost and time effective alternative to ongoing surveillance for HAI at national and sub-national levels [2-6]. By repeating such surveys trends can be accurately assessed [7].

The Canadian Nosocomial Infection Surveillance Program (CNISP) has conducted HAI surveillance in a network of Canadian hospitals since 1993. CNISP 
conducted surveys for the prevalence of HAI within network hospitals in 2002 and again in 2009, and has previously reported partial results [8-10]. In preparation for a possible repeat national survey, we wished fully compare the results of the two previous surveys to determine which developing areas may require further in-depth future review. In this report we fully describe the assessment of HAI prevalence and use of isolation precautions in patients in CNISP hospitals in 2009, compare the results to our 2002 survey, and discuss the ongoing value of HAI prevalence surveys based on these comparisons.

\section{Methods}

CNISP, a network of acute care hospitals from 10 Canadian provinces, is a partnership between the Public Health Agency of Canada (Agency) and the Canadian Hospital Epidemiology Committee, a group of hospitalbased physician infection prevention specialists. The number of hospitals participating in CNISP increased from 32 in 2002 to 50 hospitals in 2009; 7(14\%) are standalone pediatric centres. Surveillance for HAI in participating hospitals is considered to be a quality assurance activity within the mandate of hospital infection prevention and control programs and, therefore, does not constitute human research, therefore research ethics committee approval was not needed for this study.

Twenty-five (25) acute-care CNISP member hospitals with 6 pediatric hospitals and 19 combined pediatric and adult hospitals in eight provinces participated in a oneday HAI point-prevalence survey in February 2002. In February 2009, 49 hospitals including 7 pediatric and 42 combined pediatric and adult hospitals carried out a point-prevalence study. To ensure comparability of results, definitions of HAI, and case finding by chart review were identical in the 2002 and 2009 surveys. In both surveys, chart reviewers underwent pre-study training regarding HAI definitions and chart review methods. Information on HAI, utilization of antimicrobial agents and use of isolation precautions was collected. Patients were identified by a ward census list obtained at a prespecified time on the day the survey was conducted. Patients on long term care units, psychiatric units, rehabilitation units, maternity wards, well baby units and

Table 1 Characteristics of Patients Surveyed in 2009

\begin{tabular}{|c|c|c|c|c|c|c|c|c|}
\hline & \multicolumn{2}{|c|}{$\begin{array}{l}\text { All Patients } \\
N=9953\end{array}$} & \multicolumn{2}{|c|}{$\begin{array}{l}{ }^{a} \text { Adults } \\
N=8565(86.1 \%)\end{array}$} & \multicolumn{2}{|c|}{$\begin{array}{l}\text { Children } \\
N=622(6.2 \%)\end{array}$} & \multicolumn{2}{|c|}{$\begin{array}{l}\text { Infants } \\
N=729(7.3 \%)\end{array}$} \\
\hline & $\mathrm{N}$ & $\%$ & $\mathrm{~N}$ & $\%$ & $\mathrm{~N}$ & $\%$ & $\mathrm{~N}$ & $\%$ \\
\hline Male Gender ${ }^{b}$ & 5101 & 51.3 & 4367 & 51.3 & 324 & 52.1 & 394 & 54.0 \\
\hline \multicolumn{9}{|l|}{ Unit Type } \\
\hline Medicine/Pediatric & 3840 & 38.6 & 3501 & 40.9 & 226 & 36.3 & 101 & 13.9 \\
\hline Surgery & 2959 & 29.7 & 2802 & 32.7 & 123 & 19.8 & 25 & 3.4 \\
\hline Intensive Care & 1141 & 11.5 & 532 & 6.2 & 53 & 8.5 & 551 & 75.6 \\
\hline Oncology/Hematology & 350 & 3.5 & 244 & 2.8 & 98 & 15.8 & 6 & 0.8 \\
\hline Critical Care $^{d}$ & 233 & 2.3 & 233 & 2.7 & 0 & 0 & 0 & 0 \\
\hline Transplant & 177 & 1.8 & 139 & 1.6 & 33 & 5.3 & 4 & 0.5 \\
\hline Trauma & 76 & 0.8 & 71 & 0.8 & 2 & 0.3 & 3 & 0.4 \\
\hline Gynecology/Obstetrics & 157 & 1.6 & 146 & 1.7 & 0 & 0 & 7 & 1.0 \\
\hline Others & 1020 & 10.2 & 897 & 10.5 & 87 & 14.0 & 32 & 4.4 \\
\hline Total & 9953 & 100 & 8565 & 100 & 622 & 100 & 729 & 100 \\
\hline Receiving antimicrobial agent(s) & 3998 & 40.2 & 3442 & 40.2 & 329 & 52.9 & 214 & 29.4 \\
\hline \multicolumn{9}{|l|}{ Isolation Precautions ${ }^{c}$} \\
\hline None & 8483 & 85.2 & 7322 & 85.5 & 483 & 77.7 & 648 & 88.9 \\
\hline Droplet & 258 & 2.6 & 114 & 1.3 & 87 & 14.0 & 55 & 7.5 \\
\hline Air & 75 & 0.8 & 53 & 0.6 & 15 & 2.4 & 6 & 0.8 \\
\hline Contact & 1316 & 13.2 & 1136 & 13.3 & 110 & 17.7 & 64 & 8.8 \\
\hline Other & 7 & 0.07 & 4 & 0.05 & 2 & 0.32 & 1 & 0.14 \\
\hline HAl Present ${ }^{\mathrm{e}}$ & 1173 & 11.8 & 1053 & 12.3 & 66 & 10.6 & 52 & 7.1 \\
\hline
\end{tabular}

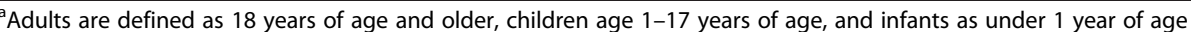

${ }^{b}$ Does not add to 9953 due to missing data

cColumns add up to a number greater than sample size due to patients being in multiple types of isolation

${ }^{d}$ Critical care refers to those patients in critical and coronary units with or without mechanical ventilation

${ }^{\mathrm{HAl}}$ Health care associated infections 
day surgery units were excluded. No patient was enrolled more than once during the surveillance period. The primary outcome was the presence of an HAI, which was defined as an infection not present on admission and with onset at least $72 \mathrm{~h}$ after admission. The study was limited to the following infections: hospital acquired pneumonia (HAP), urinary tract infection (UTI), bloodstream infection (BSI), surgical site infection (SSI) and Clostridium difficile infection (CDI). CDC/ NHSN definitions for nosocomial infection were used for all HAI [11]. Isolation precautions beyond routine practices (Additional Precautions) were categorized as defined by the Public Health Agency of Canada [12].

Patient information was collected on manually completed data forms and included: date of admission, the admitting medical or surgical service, antimicrobial agents received on the day of the survey, and isolation precautions in place on the survey day. After testing for normality, prevalence ratios were calculated and differences between infected and non-infected patients were assessed using a Wald test for categorical variables and a Student's $t$-test for continuous variables. All tests were two-tailed, and $P<0.05$ was considered statistically significant. Data analysis was performed using SAS version 8.1 (SAS Institute, Cary, NC,USA).

\section{Results}

In the 2009 survey 9,953 patients were evaluated; 8,565 (86.1) were adults (>18 years of age). $622(6.4)$ were 1 to 17 years of age, and 729 (7.3\%) were infants under the age of 1 years. Table 1 describes characteristics of surveyed patients. There were 1,231 HAI identified in 1,173 patients (11.8); 1,470 patients (16.7) were on isolation precautions and 3,998 (40.2\%) were receiving antimicrobial agents. Table 2 compares characteristics of HAI and non - HAI patients in 2009. HAI were more common in Surgery and Critical Care patients, and less frequent in Medicine and Obstetrics-gynecology patients. Patients with HAI were somewhat older and more likely to be on surgical or Intensive Care units than non-HAI patients, and more likely to be on isolation precautions and receiving antimicrobial therapy. Table 3 subdivides HAI types into Adult, Children and Infant categories, highlighting the major variation in HAI prevalence by age category. Table 4 compares the frequency and distribution of HAI in 2002 and 2009. In 2009 the prevalence

Table 2 Comparison of $\mathrm{HAl}^{\mathrm{d}}$ and non-HAl Patients Surveyed

\begin{tabular}{|c|c|c|c|c|c|}
\hline & \multicolumn{2}{|c|}{$\begin{array}{l}\text { Non-HAl Patients } \\
N=8780\end{array}$} & \multicolumn{2}{|c|}{$\begin{array}{l}\text { HAl Patients } \\
N=1173\end{array}$} & \multirow[t]{2}{*}{$P$ value } \\
\hline & $\bar{N}$ & $\%$ & $\mathrm{~N}$ & $\%$ & \\
\hline Age in years $\pm S D$ & $57.9 \pm 27.7$ & & $62 \pm 25$ & & \\
\hline Median (min-max) & $65(0-108)$ & & $68(0-99)$ & & \\
\hline Male Gender ${ }^{a}$ & 4492 & 51.2 & 609 & 51.9 & 0.6409 \\
\hline \multicolumn{6}{|l|}{ Unit Type } \\
\hline Medicine/Pediatric & 3455 & 39.4 & 385 & 32.8 & $<0.0001$ \\
\hline Surgery & 2577 & 29.4 & 382 & 32.6 & 0.0248 \\
\hline Intensive Care & 934 & 10.6 & 207 & 17.6 & $<0.0001$ \\
\hline Oncology/Hematology & 313 & 3.6 & 37 & 3.2 & 0.5543 \\
\hline Critical Care ${ }^{c}$ & 221 & 2.5 & 12 & 1.0 & 0.0007 \\
\hline Transplant & 153 & 1.7 & 24 & 2.0 & 0.4794 \\
\hline Trauma & 70 & 0.8 & 6 & 0.5 & 0.3720 \\
\hline Gynecology/Obstetrics & 149 & 1.7 & 8 & 0.7 & 0.0058 \\
\hline Others & 908 & 10.3 & 112 & 9.5 & 0.4419 \\
\hline Receiving antimicrobial agent(s) & 2925 & 33.3 & 1073 & 91.5 & 0.0001 \\
\hline \multicolumn{6}{|l|}{ Isolation Precautions ${ }^{\mathrm{b}}$} \\
\hline None & 7649 & 87.1 & 83.4 & 71.1 & 0.0001 \\
\hline Droplet & 209 & 2.3 & 49 & 4.2 & 0.0001 \\
\hline Air & 72 & 0.8 & 3 & 0.3 & 0.0305 \\
\hline Contact & 1000 & 11.4 & 316 & 26.9 & 0.0001 \\
\hline Other & 5 & 0.06 & 2 & 0.2 & 0.1955 \\
\hline
\end{tabular}

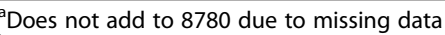

b Column adds up to a number greater than sample size due to patients being in multiple types of isolation

${ }^{c}$ Critical care refers to those patients in critical and coronary units with mechanical ventilation

${ }^{\mathrm{d}} \mathrm{HAl}$ is the abbreviation for Health care associated infections 
Table 3 Prevalence of healthcare-associated infections identified during the 2009 point prevalence survey $(N=1173)$

\begin{tabular}{|c|c|c|c|c|c|c|c|c|}
\hline \multirow[t]{2}{*}{ Type of HAl } & \multicolumn{2}{|c|}{$\begin{array}{l}\text { All HAl Patients } \\
n=1173\end{array}$} & \multicolumn{2}{|c|}{$\begin{array}{l}\text { HAl Adults } \\
n=1053(90 \%)\end{array}$} & \multicolumn{2}{|c|}{$\begin{array}{l}\text { HAI Children } \\
n=66(6 \%)\end{array}$} & \multicolumn{2}{|c|}{$\begin{array}{l}\text { HAl Infants } \\
n=52(4 \%)\end{array}$} \\
\hline & No. & $\%$ & No. & $\%$ & No. & $\%$ & No. & $\%$ \\
\hline Urinary Tract & 428 & 34.8 & 414 & 39.0 & 5 & 0.4 & 8 & 0.7 \\
\hline Pneumonia Total & 268 & 21.8 & 248 & 20.2 & 16 & 1.3 & 4 & 0.3 \\
\hline VAP & 82 & 6.7 & 71 & 5.8 & 8 & 0.7 & 3 & 0.2 \\
\hline Non VAP & 175 & 14.2 & 167 & 13.6 & 7 & 0.6 & 1 & 0.1 \\
\hline Surgical Site Total & 214 & 17.4 & 200 & 16.3 & 10 & 0.8 & 4 & 0.3 \\
\hline PI related & 63 & 5.1 & 58 & 4.7 & 5 & 0.4 & 0 & 0 \\
\hline Non PI related & 133 & 11 & 124 & 10.1 & 5 & 0.4 & 4 & 0.3 \\
\hline Blood Stream Total & 169 & 13.8 & 131 & 10.6 & 15 & 1.2 & 23 & 1.9 \\
\hline Primary, non CVC-BSI & 73 & 5.9 & 48 & 3.9 & 11 & 0.9 & 14 & 1.1 \\
\hline Primary, CVC-BSI & 29 & 2.4 & 19 & 1.5 & 2 & 0.2 & 8 & 0.7 \\
\hline Secondary & 63 & 5.1 & 60 & 4.9 & 2 & 0.2 & 1 & 0.1 \\
\hline CDI & 115 & 9.3 & 110 & 8.9 & 4 & 0.3 & 0 & 0 \\
\hline Viral Respiratory IIIness & 17 & 1.4 & 5 & 0.4 & 9 & 0.7 & 3 & 0.2 \\
\hline Viral Gastroenterocolitis & 17 & 1.4 & 0 & 0 & 10 & 0.8 & 7 & 0.6 \\
\hline NEC & 3 & 0.2 & 0 & 0 & 0 & 0 & 3 & 0.2 \\
\hline Total ${ }^{+}$ & 1231 & 100 & 1108 & 90.0 & 69 & 5.6 & 52 & 4.2 \\
\hline
\end{tabular}

Abbreviations: VAP ventilator-associated pneumonia, PI prosthetic implant, CVC-BSI central venous catheter associated blood stream infection, CDI Clostridium difficile infection, NEC Necrotizing enterocolitis

of HAI was 124 per 1000 patients surveyed, compared with 111 per 1000 in surveyed in $2002(p<0.0001)$. Between the two surveys there was a significant increase in the prevalence of UTI (from 3.0 to 4.3) and CDI (from 0.8 to $1.2 \%$ ). HAP and BSI both slightly, but significantly, decreased in prevalence. Surgical site infections were unchanged.

Figure 1 illustrates changes in prevalence of use of isolation precautions (beyond routine practices) on the survey day. There was a near doubling of use of Additional Precautions, from $77 / 1000$ survey patients in 2002 to $148 / 1000$ in $2009(p<0.0001)$, almost entirely driven by increased Contact Precautions (from 63 to 132/1000 patients). Figure 2 illustrates conditions responsible for precautions in the two surveys. As

Table 4 Comparison of Prevalence of Healthcare Associated Infections in CNISP Hospitals in 2002 and 2009

\begin{tabular}{llll}
\hline & 2002 & 2009 & $P$ value \\
\hline Participating Hospitals & 25 & 49 & \\
Surveyed patients & 6747 & 9953 & \\
Prevalence $^{\mathrm{a}}$ & 111 & 124 & $p<0.0001$ \\
Urinary tract & $3.0 \%$ & $4.3 \%$ & $p<0.0001$ \\
Surgical site & $2.3 \%$ & $2.3 \%$ & $p>0.05$ \\
Pneumonia & $2.9 \%$ & $2.7 \%$ & $p<0.0001$ \\
Blood stream & $1.8 \%$ & $1.7 \%$ & $p<0.0001$ \\
Clostridium difficile & $0.8 \%$ & $1.2 \%$ & $p<0.0001$ \\
\hline
\end{tabular}

aper 1000 survey patients indications for precautions, MRSA, CDI and VRE were all significantly increased in 2009 compared to 2002.

\section{Discussion}

CNISP has carried out two national surveys to estimate the prevalence of HAI in Canadian hospitals. The number of hospitals participating increased between the two surveys (from 25 in 2002 to 49 in 2009), however, the nature of the CNISP, hospitals network did not significantly change. Most are large urban teaching hospitals [13]. By using an identical survey tool, and standard HAI definitions for the two surveys we hoped to then evaluate changes in frequency of HAI (and related concepts, such as isolation precautions, and use of antimicrobial agents) in hospitalized patients. Based on these surveys, there was an $11.7 \%$ increase in prevalence of HAI between 2002 and 2009, largely driven by increases in UTI and CDI, partially offset by reductions in HAP and BSI. Explanations for these changes are speculative. In Canada, as elsewhere, as less acutely ill patients are increasingly managed in ambulatory settings the residual core of hospitalized patients may have higher acuity, and so may be more prone to HAI. The change in distribution of HAI is of interest. As central venous catheter and ventilator associated pneumonia (VAP) prevention bundles are implemented, reduced prevalence of BSI and HAP may occur [14,15]. We have previously documented increased incidence of CDI in CNISP hospitals [16]. An explanation for increased 


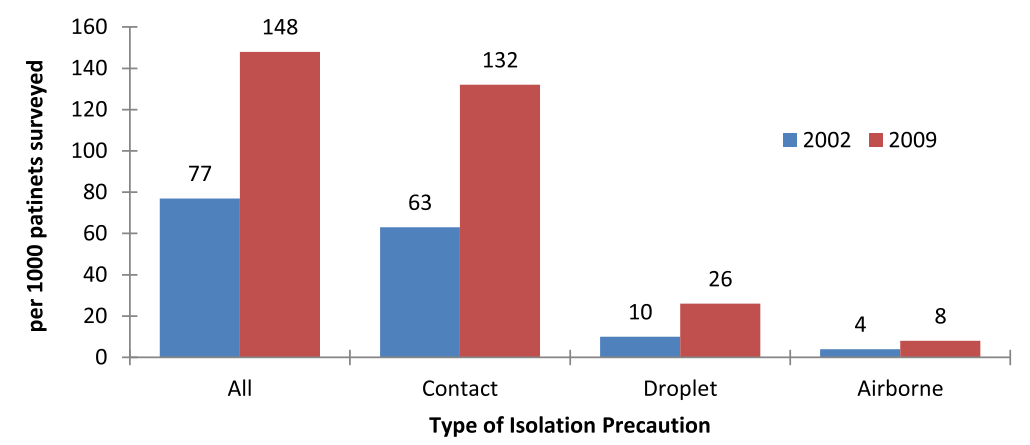

Fig. 1 Patients on additional precautions

prevalence of UTI is not apparent. The factors responsible for changing HAI distribution in Canada require further research.

Our data indicates that there was a substantial increase in use of isolation precautions in CNISP hospitals between 2002 and 2009, primarily as a result of increased use of Contact Precautions (CP). This increase in $\mathrm{CP}$ was associated with increased need for isolation of patients due to CDI, methicillin resistant Staphylococcus aureus (MRSA) and vancomycin resistant enterococci (VRE). CNISP has documented increased incidence of all of these microorganisms over the last decade [16-18]. Our prevalence surveys are observational and cannot readily assess the effectiveness of $\mathrm{CP}$ in limiting increase in CDI, MRSA or VRE frequency. Isolation precautions are used in hospitalized patients to interrupt transmission of organisms [19]. While there has been concern that transmission precautions may have adverse patient effects [20], a study of routine CP in ICU patients found no increase in adverse patient events [21] and a cohort study of non ICU patients found that patients on $\mathrm{CP}$ had a reduced frequency of non-infectious adverse events [22]. However Dhar et al. found that as the proportion of patients in CP increased, compliance with precautions decreased [23]. There is an emerging trend to reduce use of $\mathrm{CP}$ for some conditions, particularly for patients with VRE [24-27] but more research is needed to determine the most effective approach to isolation precautions in acute care settings.

Despite the relatively short interval between our two surveys, we have documented substantial changes in HAI prevalence and distribution, use of antimicrobial therapy [10] and use of isolation practices in Canadian acute care hospitals. The CNISP hospital network expanded in the years between the two surveys. While the nature of the hospitals did not systemically change, this represents a limitation in comparing results of the two surveys. CNISP hospitals are primarily tertiary care teaching and/or large urban referral hospitals [13]. This represents a limitation in the representativeness of CNISP amongst Canadian hospitals. In addition studies evaluating results of incidence and prevalence studies indicate that there is not a direct correlation between prevalence and incidence [28].

The information we report are now seven years old which is a major limitation in the data presented. It seems likely that the developing trends we have documented between 2002 and 2009 may have continued since then. Front line practitioners and healthcare administrators have an urgent need for more up to date data to permit IPC programs to be developed and

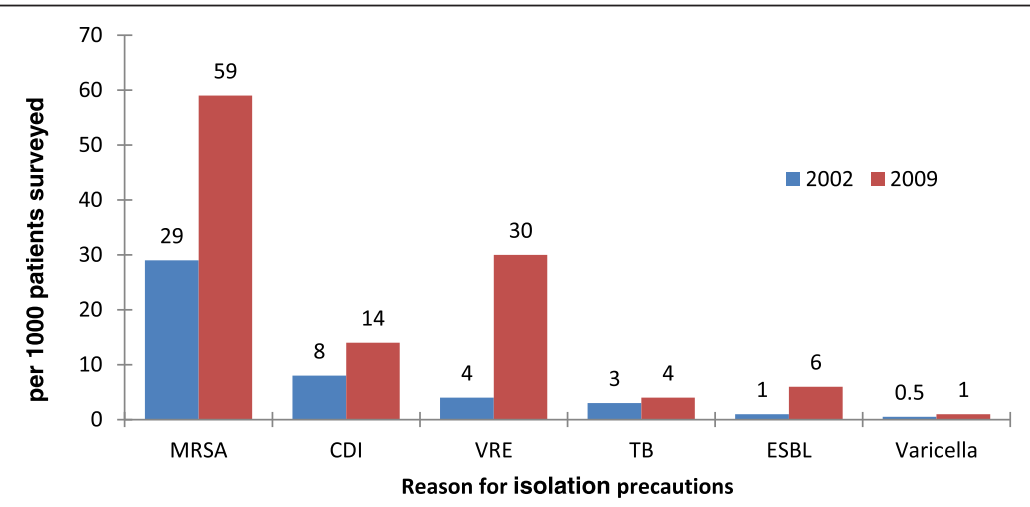

Fig. 2 Reasons for additional precautions in surveyed patients 
modified in response to the changing pattern of HAI in Canada. Consequently a repeat survey is a high priority for our network. Neverthless these data currently represents the only comprehensive estimates of the occurance of HAI in Canadian hospitals.

\section{Conclusion}

Between 2002 and 2009 in a network of acute care hospitals in Canada HAI prevalence increased from 111 to 124 per 1000 patients. The use of isolation precautions increased from 77 to 148 per 1000 patients.

\section{Availability of the data}

The database for this project is held by the Public Health Agency of Canada.

\section{Ethics statement}

Surveillance for healthcare acquired infections in in patients in participating hospitals is considered to be within the mandate of hospital infection prevention and control programs and therefore does not constitute human research requiring Institutional Review Board approval.

\section{Consent to participate \\ Not applicable.}

\begin{abstract}
Abbreviations
BSI: blood stream infection; CDI: Clostridium difficile infection; CNISP: Canadian Nosocomial Infection Surveillance Program; CP: Contact precautions; HAl: hospital acquired infection; HAP: hospital acquired pneumonia; ICU: Intensive care unit; IPC: Infection Prevention And Control; MRSA: methicillin resistant Staphylococcus aureus; SSI: surgical site infection; UTI: urinary tract infection; VAP: ventilation associated pneumonia; VRE: vancomycin resistant enterococcus.
\end{abstract}

\section{Competing interests}

The authors declare that they have no competing interests.

\section{Authors' contributions}

All authors participated in conception and study design. Other than DG, all authors contributed to data collection. DG coordinated the study and carried our data analysis. GT coordinated the study committee and wrote the manuscript. All authors read and approved the final manuscript.

\section{Acknowledgments}

We thank the infection control practitioners, and physicians, in Canadian Nosocomial Infection Surveillance Program hospitals for their invaluable work in data collection.

\section{Funding}

Funding for this project was provided by the Public Health Agency of Canada. The Agency had no role in the design of the project, the collection analysis or interpretation of the data, or the writing and approval of the manuscript.

Members of the Canadian Nosocomial Infection Surveillance Program David Boyd, National Microbiology Laboratory, Public Health Agency of Canada; Natalie Bridger, Eastern Health-Health Sciences Centre, St. John's, Newfoundland; Elizabeth Bryce, Vancouver Coastal Health Authority, Vancouver, British Columbia; John Conly, Foothills Medical Centre, Calgary, Alberta; André Dascal, Sir Mortimer B. Davis-Jewish General Hospital, Montreal, Quebec; Janice de Heer, Interior Health Authority, Kelowna, British Columbia; John Embil, Health
Sciences Centre, Winnipeg, Manitoba; Joanne Embree, Health Sciences Centre, Winnipeg, Manitoba; Gerald Evans, Kingston General Hospital, Kingston, Ontario; Sarah Forgie, Stollery Children's Hospital, Edmonton, Alberta; Charles Frenette, McGill University Health Centre, Montreal, Quebec; David Haldane, Queen Elizabeth II Health Sciences Centre, Halifax, Nova Scotia; Gregory German, Queen Elizabeth Hospital, Charlottetown, Prince Edward Island; George Golding, National Microbiology Laboratory, Public Health Agency of Canada; Denise Gravel, Centre for Communicable Diseases and Infection Control, Public Health Agency of Canada; Deanna Hembroff, University Hospital of Northern British Columbia, Prince George, British Columbia; Elizabeth Henderson, Alberta Health Services, Calgary, Alberta; Michael John, London Health Sciences Centre, London, Ontario; Lynn Johnston, Queen Elizabeth II Health Sciences Centre, Halifax, Nova Scotia; Kevin Katz, North York General Hospital, Toronto, Ontario; Pamela Kibsey, Victoria General Hospital, Victoria, British Columbia; Magdalena Kuhn, South East Regional Health Authority, Moncton, New Brunswick; Joanne Langley, IWK Health Centre, Halifax, Nova Scotia; Camille Lemieux, University Health Network, Toronto, Ontario; Nicole Le Saux, Children's Hospital of Eastern Ontario, Ottawa, Ontario; Mark Loeb, Hamilton Health Sciences Corporation, Hamilton, Ontario; Susan Richardson, Hospital for Sick Children, Toronto, Ontario; Allison McGeer, Mount Sinai Hospital, Toronto, Ontario; Dominik Mertz, Hamilton Health Sciences Corporation, Hamilton, Ontario; Mark Miller, Sir Mortimer B. Davis-Jewish General Hospital, Montreal, Quebec; Robyn Mitchell, Centre for Communicable Diseases and Infection Control, Public Health Agency of Canada; Dorothy Moore, Montreal Children's Hospital, McGill University Health Centre, Montreal, Quebec; Aboubakar Mounchili, Centre for Communicable Diseases and Infection Control, Public Health Agency of Canada; Michael Mulvey, National Microbiology Laboratory, Public Health Agency of Canada; Suzanne Pelletier, Health Sciences North, Sudbury, Ontario; Linda Pelude, Centre for Communicable Diseases and Infection Control, Public Health Agency of Canada; Caroline Quach, Montreal Children's Hospital, McGill University Health Centre, Montreal, Quebec; Virginia Roth, The Ottawa Hospital, Ottawa, Ontario; Andrew Simor, Sunnybrook Health Sciences Centre, Toronto, Ontario; Stephanie Smith, University of Alberta Hospital, Edmonton, Alberta; Kathryn Suh, The Ottawa Hospital, Ottawa, Ontario, Geoffrey Taylor, University of Alberta Hospital, Edmonton, Alberta; Eva Thomas, Children's and Women's Health Center, Vancouver, British Columbia; Nathalie Turgeon, Centre Hospitalier de Universitaire de Québec-Hôtel-Dieu, Quebec, Quebec; Mary Vearncombe, Sunnybrook Health Sciences Centre, Toronto, Ontario; Joseph Vayalumkal, Alberta Children's Hospital, Calgary, Alberta; Karl Weiss, Maisonneuve-Rosemont Hospital, Montreal, Quebec; Alice Wong, Royal University Hospital, Saskatoon, Saskatchewan.

\section{Author details \\ ${ }^{1}$ University of Alberta Hospital, 1-127 CSB, T6G 2G3 Edmonton, Alberta, Canada. ${ }^{2}$ Centre for Communicable Diseases and Infection Control, Public Health Agency of Canada, Ottawa, Ontario, Canada. ${ }^{3}$ University of Alberta Hospital, Edmonton, Alberta, Canada. ${ }^{4}$ The Hospital for Sick Children, Toronto, Ontario, Canada. ${ }^{5}$ Health Sciences Centre, Winnipeg, Manitoba, Canada. ${ }^{6}$ The Ottawa Hospital, Ottawa, Ontario, Canada. ${ }^{7}$ Queen Elizabeth II Health Sciences Centre, Halifax, Nova Scotia, Canada. ${ }^{8}$ Health Sciences Centre, London, Ontario, Canada. ${ }^{9}$ Alberta Heath Services, Calgary, Alberta, Canada. ${ }^{10}$ Royal University Hospital, Saskatoon, Saskatchewan, Canada.}

Received: 9 February 2016 Accepted: 10 May 2016

Published online: 21 May 2016

References

1. Klevens RM, Edwards JR, Richards Jr CL, et al. Estimating health care associated infections and deaths in U.S. hospitals, 2002. Public Health Rep. 2007;122:160-6

2. Llata E, Gaynes R, Fridkin S. Measuring the scope and magnitude of hospital-associated infection in the United States: the value of prevalence surveys. CID. 2009:48:1434-40.

3. The French Prevalence Survey Study Group. Prevalence of nosocomial infections in France: results of the nationwide survey in 1996. J Hosp Infect. 2000:46:186-93.

4. Eriksen HM, Iversen B, Aavitsland P. Prevalence of nosocomial infections in hospitals in Norway, 2002 and 2003. J Hosp Infect. 2005;60:40-5.

5. Gikas A, Pediaditis J, Papadakis JA, et al. Prevalence study of hospital acquired infections in 14 Greek hospitals: planning from the local to the national surveillance level. J Hosp Infect. 2002;50:269-75. 
6. Danchaivijitr S, Judaeng T, Sripalakij S, Naksawas K, Plipat T. Prevalence of nosocomial infection in Thailand 2006. J Med Assoc Thai. 2007;90:1524-9.

7. Zingg W, Huttner B, Sax H, Pittet D. Assessing the burden of healthcareassociated infections through prevalence studies: What is the best method? Infect Control Hosp Epidemiol. 2014;36(6):674-84.

8. Gravel D, Taylor G, Ofner M, et al. Point prevalence survey for health-care associated infections within Canadian adult acute care hospitals. J Hosp Infect. 2007;66:243-8.

9. Rutledge-Taylor K, Matlow A, Gravel D, et al. A point prevalence survey of health-care associated infections in Canadian pediatric inpatients. Am J Inf Contr. 2012;40:491-6.

10. Taylor G, Gravel D, Saxinger L, Bush K, Simmonds K, Matlow A, Embree J, Le Saux N, Johnston L, Suh K, Embil J, Henderson E, John M, Roth V, Wong A. Prevalence of antimicrobial use in a network of Canadian hospitals in 2002 and 2009. Can J Infect Dis Med Microbiol. 2015:26(2):85-9.

11. CDC/NHSN surveillance definitions for specific types of infections. January 2015. Retrieved from http://www.cdc.gov/nhsn/PDFs/pscManual/ 17pscNosInfDef_current.pdf.

12. Public Health Agency of Canada. Routine practices and additional precautions for preventing the transmission of infection in healthcare settings. September 2014. Retrieved from URL http://www.phac-aspc.gc. ca/nois-sinp/guide/summary-sommaire/tihs-tims-eng.php.

13. Rutledge-Taylor K, Mitchell R, Pelude L, AbdelMalik P, Roth V. Evaluation of the representativeness of the Canadian Nosocomial Infection Surveillance Program. Can J Infect Control. 2015;30(1):13-7.

14. Pronovost $P$, Needham D, Berenholtz $S$, Sinopoli D, Chu H, Cosgrove $S$, Sexton B, Hyzy R, Welsh R, Roth G, Bander J, Kepros J, Goeschel C. An intervention to decrease catheter-related bloodstream infections in the ICU. N Engl J Med. 2006;355:2725-32.

15. Branch-Elliman $E$ et al. Determining the ideal strategy for ventilatorassociated pneumonia prevention: cost-benefit analysis. Am J Respir Crit Care Med. 2015:192:57.

16. Gravel D, Miller M, Simor A, et al. Health care-associated clostridium difficile infection in adults admitted to acute care hospitals in Canada: a Canadian nosocomial infection surveillance program study. Clin Infect Dis. 2009;48:568-76.

17. Simor AE, Gilbert N, Gravel D, Mulvey MR, Bryce E, Loeb M, Matlow A, McGeer A, Louie L, Campbell J, and the Canadian Nosocomial Infection Surveillance Program. And the Canadian nosocomial infection surveillance program. Methicillin-resistant staphylococcus aureus in Canada: national surveillance and changing epidemiology, 1995-2007. Infect Control Hosp Epidemiol. 2010;31(4):348-56.

18. Ofner-Agostini $M$, Johnston $L$, Simor A. Vancomycin resistant enterococci in Canada: results from the Canadian nosocomial infection surveillance program, 1999-2005. Inf Control Hosp Epidemiol. 2008;29:271-4.

19. Harris $A D$, Pineles $L$, Belton $B$, et al. Benefits of universal glove and gown (BUGG) investigators. Universal glove and gown use and acquisition of antibiotic-resistant bacteria in the ICU: a randomized trial. JAMA. 2013;310:1571-80.

20. Abad C, Fearday A, Safdar N. Adverse effects of isolation in hospitalised patients: a systemic review. J Hosp Infect. 2010;76(2):97-102.

21. Croft L, Harris A, Pineles L, Langenberg P, Shardell M, Fink J, Simoni-Wastila $L$, Morgan D. The effect of universal glove and gown use on adverse events in intensive care unit patients. Clin Infect Dis. 2015;61:545-53.

22. Croft L, Liquori M, Ladd J, Day H, Pineles L, Lamos E, Arnold R, Mehrotra P, Fink J, Langenberg P, Simoni-Wastila L, Perencevich E, Harris A, Morgan D. The effect of contact precautions on frequency of hospital adverse events. Infect Control Hosp Epidemiol. 2015;36(11):1268-74.

23. Dhar S, Marchaim D, Tansek R, Chopra T, Yousuf A, Bhargava A, Martin ET, albot TR, Johnson LE, Hingwe A, Zuckerman JM, Bono BR, Shuman EK, Poblete J, Tran M, Kulhanek G, Thyagarajan R, Nagappan V, Herzke C, Perl TM, Kaye KS. Contact precautions: more is not necessarily better. Infect Control Hosp Epidemiol. 2014;35(3):213-21.

24. Kirkland K. Taking off the gloves: toward a less dogmatic approach to the use of contact isolation. Clin Infect Dis. 2009;45:766-71.

25. Bryce E, Grant J, Scharf S, Dempster L, Lau T, Laing F, Shajari S, Forrester L. Horizontal infection prevention measures and a risk-managed approach to vancomycin-resistant enterococci: an evaluation. Am J Infect Control. 2015; 16 [Epub ahead of print]

26. Popiel K, Miller M. Evaluation of vancomycin-resistant enterococci (VRE)-associated morbidity following relaxation of VRE screening and isolation precautions in a tertiary care hospital. Infect Control Hosp Epidemiol. 2014;35(7):818-25.
27. Morgan DJ, Murthy R, Munoz-Price LS, Barnden M, Camins BC, Johnston BL, Rubin Z, Sullivan KV, Shane AL, Dellinger EP, Rupp ME, Bearman G. Reconsidering contact precautions for endemic methicillin-resistant staphylococcus aureus and vancomycin-resistant Enterococcus. Infect Control Hosp Epidemiol. 2015;3:1-10 [Epub ahead of print].

28. Gastmeier P, Brauer H, Sohr D, Geffers C, Forster D, Daschner F, Ruden H. Converting incidence and prevalence data of nosocomial infections: results from eight hospitals. Infect Control Hosp Epidemiol. 2001;22(1):31-4.

\section{Submit your next manuscript to BioMed Central and we will help you at every step:}

- We accept pre-submission inquiries

- Our selector tool helps you to find the most relevant journal

- We provide round the clock customer support

- Convenient online submission

- Thorough peer review

- Inclusion in PubMed and all major indexing services

- Maximum visibility for your research

Submit your manuscript at www.biomedcentral.com/submit
Biomed Central 